\title{
KESANTUNAN OFF RECORD TINDAK DIREKTIF DALAM KALIMAT DEKLARATIF BAHASA JEPANG
}

\author{
Desy Irmayanti \\ Universitas Dr. Soetomo, desyirma05@gmail.com
}

\begin{abstract}
Pragmatics is the study of meaning which is involved three aspects (triadic) spoken by the speaker or the writer and translated by the listener or the reader. This study aim at analyzing the politeness strategy in the delivery of directive utterances in the dialog of the characters in Japanese drama called Sapuri and Osen. The study which uses the qualitative method, applies documentation method in collecting the data from the dialogue of the characters in Japanese drama called Sapuri and Osen. By using recording method, the form of directive utterances can be determined. Meanwhile, the meaning and politeness strategy of directive utterances are obtained by observation method. The result of the study shows that politeness strategy which is the most spoken in both Japanese Drama (according to the most spoken) is give association clues, give hints, presuppose, use tautologies, under state, use rhetorical questions, overstate, use contradiction, use metaphors, be vague, be incomplete or use ellipsis, be ironic, and over generalize. No data are found for be ambiguous and displace hearer of politeness strategy.
\end{abstract}

Key Words: directive utterance, politeness strategy, off record

\section{PENDAHULUAN}

Latar Belakang

Sebagai alat komunikasi dalam melakukan interaksi antar sesama manusia, bahasa mempunyai peranan yang sangat penting. Penggunaan bahasa tersebut baik lisan maupun tulis mempunyai tujuan yang sama, yaitu untuk menyampaikan pesan atau maksud kepada lawan bicara. Supaya pesan tersebut bisa tersampaikan dengan baik, penutur perlu memahami bahasa yang digunakan. Selain itu, untuk menghindari terjadinya kesalahpahaman yang bisa membuat lawan tutur tersinggung, marah atau sebaliknya menimbulkan penilaian yang tidak baik terhadap penutur itu sendiri, maka penutur perlu memiliki kemampuan memilih dan mengolah kata. 
Kemampuan mengolah dan memilih kata yang tepat dan sesuai tersebut merupakan salah satu cara untuk menunjukkan rasa hormat atau santun. Selain cara tersebut, penutur juga dapat menggunakan tuturan tidak langsung atau menyembunyikan maksud yang sebenarnya kepada lawan tutur untuk meminta. Demikian pula tuturan dalam bahasa Jepang. Supaya tuturan yang diucapkan kelihatan lebih santun, maka tuturan tersebut akan diucapkan semakin tidak langsung dan tidak efektif.

Selain bentuk tuturan, pemahaman konteks juga mempunyai peranan penting dalam berkomunikasi supaya tidak terjadi kesalahpahaman. Oleh karena itu muncul kajian linguistik yang disebut dengan pragmatik. Leech (2011:8) menyebutkan bahwa pragmatik adalah kajian linguistik dimana makna diberlakukan sebagai suatu hubungan yang melibatkan tiga segi (triadic) dan dalam hubungannya dengan penutur atau pemakai bahasa. Adanya kesamaan latar belakang pengetahuan (mengenai tuturan yang sedang dibicarakan) antara penutur dan petutur, maka keduanya dapat melakukan komunikasi dengan lancar.

Tindak tutur dan peristiwa tutur merupakan dua hal mendasar yang berhubungan dengan suatu tuturan. Yule (2006:82) menjelaskan bahwa tindakantindakan yang ditampilkan lewat suatu tuturan disebut dengan tindak tutur. Sedangkan keadaan disekitar lingkungan termasuk juga tuturan-tuturan yang lain disebut dengan peristiwa tutur. Ada tiga jenis tindak tutur yang dihasilkan oleh suatu tindakan bertutur, yaitu tindak lokusi, tindak ilokusi dan tindak perlokusi. Hubungan ketiga tindak tutur tersebut tidak dapat dipisahkan antara satu dan yang lainnya.

Dalam menjalin suatu hubungan dalam berkomunikasi, tindak tutur ilokusilah yang mempunyai jenis dan fungsi tuturan diantara ketiga tindak tutur lainnya. Searle (dalam Leech, 1993:162) membagi jenis tindak tutur ilokusi 
menjadi lima macam, yaitu asertif, komisif, direktif, ekspresif, dan deklarasi. Sedangkan fungsi tindak tutur ilokusi terdiri dari empat jenis, yaitu fungsi kompetitif, fungsi bekerjasama, fungsi menyenangkan, dan fungsi bertentangan.

Tindak tutur direktif mempunyai tujuan menghasilkan suatu efek berupa tindakan yang dilakukan oleh mitra tutur (Leech, 2011:164). Setiap tuturan dari seorang penutur mempunyai fungsinya tersendiri sesuai dengan tujuannya yaitu untuk berkomunikasi. Suatu strategi yang tepat sangat diperlukan agar tujuan berkomunikasi dapat berjalan dengan baik, salah satunya adalah dengan menggunakan prinsip kesopanan. Prinsip kesopanan adalah prinsip yang mengatur suatu tuturan agar terdengar santun oleh lawan tutur. Yule (2006:104) mengatakan bahwa kesopanan merupakan alat yang digunakan untuk menunjukkan kesadaran tentang wajah orang lain. Wajah yang dimiliki oleh setiap orang mengacu pada makna sosial dan emosional itu sendiri karena wajah merupakan wujud pribadi seseorang dalam masyarakat yang mengharapkan orang lain mengetahuinya.

Teori mengenai prinsip kesantunan banyak dikemukakan oleh para ahli. Salah satuya adalah teori tentang strategi kesantunan oleh Brown dan Levinson yang dikenal dengan pandangan "penyelamatan wajah atau penyelamatan muka (face-saving)". Rahardi (2005:39) menjelaskan bahwa Brown dan Levinson membagi muka menjadi dua yaitu muka positif (positive face) yang menunjuk pada keinginan untuk disetujui (being approved) dan muka negatif (negative face) yang menunjuk pada keinginan untuk menentukan diri sendiri (selfdeterminating).

Pada komunikasi interpersonal dapat dikatakan bahwa muka seseorang selalu berada dalam keadaan terancam. Brown dan Levinson menyebut keadaan terancam tersebut dengan tindakan mengancam muka (face threatening Act/FTA). Oleh karena itu muka seseorang harus diselamatkan dalam kegiatan bertutur. Untuk itulah prinsip kesantunan diperlukan dalam bertutur (Rahardi, 2005:39). 
Agar dapat memahami bagaimana penggunaan strategi kesantunan Brown dan Levinson tersebut, penulis menggunakan serial drama Jepang berjudul Sapuri dan Osen sebagai sumber data. Dialog dalam kedua serial drama tersebut berupa dialog yang lazim ditemui dalam kehidupan nyata karena ceritanya diangkat dari kisah yang bisa saja terjadi di dalam kehidupan sehari-hari. Selain itu tentu saja banyak strategi kesantunan yang digunakan oleh para tokoh dalam dialognya.

\section{PEMBAHASAN}

\section{Tindak Direktif}

Tindak tutur direktif mempunyai tujuan menghasilkan suatu efek berupa tindakan yang dilakukan oleh mitra tutur (Leech, 2011:164). Senada dengan Leech, Kreidler (1998:190) menjelaskan bahwa tindak tutur direktif adalah tuturan yang mempunyai tujuan berusaha menyuruh lawan tutur untuk melakukan atau tidak melakukan suatu perbuatan tertentu. Tuturan direktif bersifat prospektif, yaitu kita tidak mungkin menyuruh orang lain melakukan sesuatu di masa lampau.

Bentuk tuturan direktif jenisnya sangat beragam. Yule (2006:93) membagi bentuk tuturan direktif menjadi empat jenis, yaitu: (1) perintah, (2) pemesanan, (3) permohonan, dan (4) pemberian saran. Namun Kreidler (1998:190-191) membagi bentuk tuturan direktif menjadi tiga besar dengan rincian yang lebih detail, yaitu:

1. A command atau perintah. Tuturan direktif dengan bentuk perintah ini hanya efektif jika pembicara bisa mengendalikan sampai tingkat tertentu tindakan orang yang disapa. Predikat yang dapat digunakan dalam ungkapan perintah ini dapat berbentuk positif dan negatif. Bentuk positif berupa kata-kata charge (menuntut), command (memerintah), direct (mengarahkan), order 
(menyuruh), dan demand (meminta dengan tegas). Sedangkan bentuk negatif berupa kata forbid (larangan).

Contoh: the boss demands that these letters (should) go out today.

'Atasan tersebut meminta dengan tegas supaya hari ini surat-surat tersebut sudah terkirim'

2. A request atau permintaan, adalah ungkapan mengenai apa yang diinginkan pembicara agar dilakukan atau tidak dilakukan oleh lawan bicara. Permintaan tidak berasumsi bahwa pembicara dapat mengendalikan lawan bicara. Makna umum: seorang pembicara, yang tidak berwenang, mengungkapkan keinginannya bahwa lawan bicara (tidak) bertindak sesuai dengan keinginan pembicara. Predikat yang dapat digunakan dalam ungkapan permintaan ini bisa berupa appeal (meminta) dan petition (memohon).

Contoh: I appeal to you to help as much as you can.

' Saya meminta Anda untuk membantu semampu Anda'

3. Suggestions atau usulan, merupakan ungkapan yang disampaikan kepada orang lain untuk mengemukakan pendapat mengenai apa yang sebaiknya mereka lakukan atau tidak lakukan. Makna umum: seorang pembicara mengungkapkan pendapat tentang pilihan tindakan orang yang disapa. Orang yang disapa belum tentu orang yang diberi saran. Prasyarat: orang yang diberi saran memiliki pilihan dalam tindakannya. Predikat yang dapat digunakan dalam ungkapan usulan ini dapat berbentuk positif dan negatif. Untuk yang berbentuk positif dapat berupa advise (menasehati), counsel (menganjurkan), dan recommend (merekomendasi). Sedangkan yang berbentuk negatif dapat berupa caution (memperingati) dan warn (memperingatkan)

Contoh: I warn you not to be late.

'Saya memperingatkan Anda supaya tidak terlambat'

Strategi Kesantunan Off Record

http://iournal.unesa.ac.id/index.php/paramasastra | 226 
Untuk menjaga muka peserta komunikasi atau untuk memperkecil acaman terhadap muka, maka Brown dan Levinson (1987:69) mengajukan strategi kesantunan yaitu: (1) Melakukan FTA secara Bald on Record (apa adanya), dan (2) Melakukan FTA secara Off Record (pelunakan). Strategi Bald on Record (apa adanya) terdapat pada ujaran imperatif dengan tindak tutur langsung. Sedangkan strategi Off Record (pelunakan) terdapat pada tindak tutur tidak langsung.

Strategi off record digunakan untuk memperhalus suatu ujaran. Karena pada dasarnya strategi off record terdapat pada tindak tutur tidak langsung, maka lawan bicara terkadang harus menginterpretasikan sendiri ujaran yang dituturkan tersebut. Brown dan levinson (1987:213-227) membaginya menjadi lima belas strategi yang dikelompokkan menjadi dua kelompok, yaitu:

1. Menggunakan implikatur percakapan (Invite conversational implicature), yaitu perlunya seorang penutur memberikan beberapa petunjuk atau isyarat (hint) kepada lawan tutur bila penutur ingin melakukan FTA secara tidak langsung. Dengan petunjuk tersebut lawan tutur diharapkan memahaminya dan bisa menginterpretasikan maksud tuturan yang diujarkan oleh penutur. Pada dasarnya strategi ini dilakukan dengan menggunakan implikatur-implikatur percakapan dan melanggar keefisienan komunikasi maksim Grice.

a. Memberikan isyarat atau petunjuk (Give hints), yaitu penutur mengujarkan sesuatu yang tidak berhubungan dengan maksud yang sebenarnya, ia berharap lawan bicaranya dapat menginterpretasikan ujaran yang disampaikan tersebut.

Contoh: What a hot day! (how about a drink)

'hari yang panas' (bagaimana kalau segelas minuman)

What a boring movie! (let's leave)

'film yang sangat membosankan!' (ayo kita pergi)

b. Memberi petunjuk yang berhubungan (Give association clues), yaitu penutur mengujarkan sesuatu yang berhubungan dengan tindakan yang 
diharapkan dari lawan bicara karena penutur dan lawan tutur sebelumnya telah mengalami suatu pengalaman yang sama.

Contoh: Oh God, I've got a headache again

'oh Tuhan, kepalaku sakit lagi'

Are you going to market tomorrow?...there's a market tomorrow, I suppose (Give me a ride there)

'apakah Anda akan ke pasar besok? ...besok akan ada pasar, aku seharusnya (beri aku tumpangan)'

c. Praanggapan (Presuppose), yaitu penutur menuturkan ujaran yang seluruhnya hampir relevan dengan konteks dengan memberikan praanggapan.

Contoh: I wash the car again today.

'Hari ini aku mencuci mobi lagi'

John's in the bathup yet again

'John belum mandi lagi'

It wasn't me that did it.

'Bukan aku yang melakukan hal itu'

d. Mengecilkan (Understate), yaitu penutur memberi nilai lebih atas sesuatu hal dengan maksud memperhalus ujarannya atau dengan tidak memberikan (menyembunyikan) yang sebenarnya. Hal tersebut dilakukan oleh penutur dengan maksud menjaga muka.

Contoh: A: What do you think of Harry?

'Bagaimana Harry menurut mu?'

$B$ : Nothing wrong with him. (I don't think he's very good)

'tidak ada yang salah dengan dia'

(Aku tidak berpikir kalau dia sangat bagus)

A: How do you like Josephine's new haircut?

'apakah Anda menyukai gaya rambut Josephine yang baru?'

B: It's $\left\{\begin{array}{c}\text { Pretty nice } \\ \text { all right } \\ \text { OK }\end{array}\right\}$ (I don't particularly like it)

‘itu $\left\{\begin{array}{c}\text { cantik } \\ \text { cukup bagus } \\ \text { OK }\end{array}\right\}$ (aku tidak begitu menyukainya) 
e. Melebihkan (Overstate), yaitu penutur menuturkan ujaran yang lebih atau menuturkan ujaran yang jauh dari kebenaran.

Contoh: There were a million people in the Co-op tonight! 'ada jutaan orang di koperasi malam ini!'

I tried to call a hundred times, but there was never any answer. 'aku mencoba menelepon seratus kali, tapi tidak pernah ada jawaban'

f. Menggunakan tautologi (Use tautologies), yaitu penutur menuturkan ujaran dengan taulogi (pengulangan kata tanpa penjelasan) dengan harapan kawan bicara dapat menginterpretasikan ujaran yang tidak informatif tersebut.

Contoh: War is war. 'perang adalah perang' If I won't give it, I won't 'jika aku tidak mau memberikan, aku tidak akan memberikannya'

g. Menggunakan kontradiksi (Use contradiction), yaitu penutur menuturkan ujaran yang saling bertentangan. Dengan menuturkan dua hal yang saling bertentangan, penutur menunjukkan bahwa ia tidak dapat mengatakan yang sebenarnya dan berharap lawan bicara dapat mencari interpretasi dari ujaran tersebut.

Contoh: A: Are you upset about that? 'apakah Anda sedih kecewa tentang hal itu?'

B: Well, yes and no. 'ya dan tidak' Iam and I'm not 'ya dan tidak'

h. Menggunakan ironi (Be ironic), yaitu penutur menuturkan ujaran dengan cara penggunaan ironi.

Contoh: Beautiful weather, isn't it! (to postman drenched in rainstorm) 'cuaca yang cerah, bukan?

(kepada seorang tukang pos yang basah kuyup karena hujan lebat) John's a real genius. (after John has just done twenty stupid things in a row) 
'John benar-benar jenius'

(setelah John melakukan 20 hal bodoh secara terus menerus)

i. Menggunakan metafora (Use metaphors), yaitu penutur menuturkan ujaran dengan menggunakan metafora atau kiasan.

Contoh: Harry's a real fish. (He \{is slimy, swims, is cold-blooded, drinks, $\}$ like a fish)

'Harry benar-benar seekor ikan.

Dia (kurus, berenang, berdarah dingin, minum) seperti seekor ikan.

The main thing is that (he) 'eat kicks'. (let him suffer)

'yang terpenting adalah (dia) menderita' (biarkan dia menderita)

j. Menggunakan retorika (Use rhetorical questions), yaitu penutur menuturkan ujarannya dengan retorika.

Contoh: Did he (ever, even) come to visit me once while I was in hospital?

'Apakah (pernakah) dia mengunjungi ku sekali ketika aku di RS?'

How many times do I have to tell you...? (too many)

'berapa kali aku harus mengatakan kepada mu?'...(berkali-kali)

2. Samar atau ambigu (Be vague or ambiguous), yaitu penutur lebih memilih untuk menggunakan strategi off record secara samar atau tidak jelas maksudnya.

k. Ambigu (Be ambiguous), yaitu penutur menuturkan ujaran yang maksudnya tidak jelas antara makna literal dan implikatur. Umumnya dilakukan dengan menggunakan metafora, mengingat penggunaan metafora ini tidak selalu jelas konotasi metafora mana yang digunakan.

Contoh: John's pretty (sharp, smooth) cookie.

'kue John yang manis (tajam, halus)

1. Samar (Be vague), yaitu penutur menuturkan ujaran yang tidak jelas (menyamarkan) siapa objek atau apa maksudnya.

Contoh: Perhaps someone did something naughty.

'mungkin seseorang telah melakukan kenakalan'

Looks like someone may have had too much to drink. (vague

under-statement)

'kelihatannya seseorang telah terlalu banyak minum' 
m. Penutur menuturkan ujaran suatu objek secara umum atau tidak khusus (Over-generalize)

Contoh: Mature people sometimes help do the dishes. 'orang yang dewasa kadang membantu mencuci piring' A penny saved is a penny earned. 'uang yang ditabung adalah uang yang diterima'

n. Menggantikan lawan bicara (Displace Hearer), yaitu penutur menuturkan ujarannya bukan kepada objek aslinya tetapi kepada orang lain. Hal ini bertujuan supaya target sebenarnya dapat mengetahui bahwa sasaran FTA sesungguhnya adalah dirinya.

Contoh: Seorang sekretaris meminta tolong temannya untuk mengambilkan stappler. Tetapi, stappler tersebut sebenarnya lebih dekat dengan atasannya. Suatu hal yang tidak sopan meminta atasannya untuk mengambilkan stappler tersebut. Maka dia meminta temannya, Padahal stappler tersebut lebih dekat dengan atasannya.

o. Tidak lengkap, menggunakan elipsis (Be incomplete, use ellipsis), yaitu penutur menuturkan ujaran yang maksudnya masih menggantung atau tidak menyelesaikan ujarannya sehingga maksudnya tidak jelas.

Contoh: Well, I didn't see you.... 'ngomong-ngomong, aku tidak melihat mu...' Oh sir, a headache.... 'aduh pak, sakit kepala...'

\section{Kalimat Deklaratif}

Kalimat adalah bagian yang memiliki serangkaian makna yang ada di dalam suatu wacana yang dibatasi dengan tanda titik. Kalimat dalam bahasa Jepang disebut dengan bun. Di dalam ragam lisan sebuah kalimat ditandai dengan penghentian pengucapan pada bagian akhir kalimat tersebut. Iwabuchi (dalam Sudjianto, 2012:140). Keberadaan sebuah kalimat akan tampak lebih jelas dalam 
ragam tulisan karena pada bagian akhirnya selalu ditandai dengan tanda titik, ditandai juga dengan tanda tanya atau tanda seru.

Menurut Kindaichi (1988:216) Kalimat dalam bahasa Jepang awalnya diklasifikasikan menjadi kalimat deklaratif (declarativel 平叙文 ‘heijobun’), interogatif (interrogativel 疑問文' gimonbun'), imperatif (imperativel 命令文 'meireibun'), dan eksklamatif (exclamatory/ 感 動 文 'kandoubun'). Pengklasifikasian ini merupakan adaptasi dari sistem lama yang digunakan di Eropa. Tetapi, klasifikasi ini tidak sesuai dengan karakter kalimat bahasa Jepang. Subjek dalam kalimat bahasa Jepang sangat samar dan dalam beberapa kasus jarang digunakan. Urutan elemen struktur kalimat dalam bahasa Jepang sangat stabil sehingga tidak terpengaruh oleh perubahan jenis kalimatnya. Oleh karena itu pengklasifikasian kalimat dalam bahasa Jepang harus didasarkan pada hal yang berbeda.

Yasushi (dalam Kindaichi, 1988:218) mengklasifikasikan kalimat bahasa Jepang menjadi tiga yaitu:

1. Kalimat Deklaratif (述定 ‘jutsuteibun’), yaitu kalimat yang mengekspresikan sikap penutur tentang sesuatu hal yang diungkapkan, antara lain,

a. Generalisasi dengan keputusan (generalisation by decision/断定による統 括)

Contoh: Ame ga furu (hujan turun)

Hana ha utsukushii (bunganya indah)

b. Keragu-raguan (doubt / 疑い)

Contoh: Ame ga furu kashira (Sepertinya mau hujan)

Kimi wa gakusei ka? (Apa kamu mahasiswa?)

c. Dugaan + perasaan (supposition + emotion / 推量 + 感動)

Contoh: Ame ga furu darou naa! (Oh, mau hujan!)

d. Kebulatan tekad (determination / 決意)

Contoh: Zehi atte miyou (Ayo bertemu) 
Desy Irmayanti, Kesantunan Tindak Direktif... (hIm.222-239)

Nido to kaumai (Aku tidak akan membelinya lagi)

e. Keputusan + perasaan (decision + emotion / 断定十感動)

Contoh: Ame! (Hujan!)

Ame da! (Hujan!)

f. Perasaan (emotion / 感動)

Contoh: Ara! (Oh!)

2. Kalimat Transmitif ( 伝達文 'dentatsubun'), yaitu kalimat yang mengekspresikan perasaan penutur akan pengaruhnya terhadap lawan tutur, antara lain,

a. Perintah (command/ 命令)

Contoh: Ike! (Pergi!)

b. Ajakan (invitation / 誘い)

Contoh: Kanpai! (Bersulang!)

c. Sapaan (Address/呼びかけ)

Contoh: Ojousan! (Nona!)

d. Tanggapan (response / 応答)

Contoh: Hai (Iya)

3. Kalimat Deklaratif-Transmitif (述定文 ‘jutsuteibun’ + 伝達文 ‘dentatsubun’), yaitu kalimat yang mengekspresikan sikap penutur terhadap suatu hal yang diungkapkan dan perasaan penutur akan pengaruhnya terhadap lawan bicara, antara lain,

a. Keputusan+pemberitahuan (decision+announcement / 断定十告知)

Contoh: Ame ga furu yo (Mau hujan lho)

b. Keputusan+perasaan+pemberitahuan (decision+emotion+announcement/ 断定十感動十告知)

Contoh: Ame ga furu wa yo (Oh, mau hujan lho) 
c. Dugaan+konfirmasi (supposition+proposal / 推量十もちかけ)

Contoh: Ame ga furu darou ne? (Mau hujan kan ya?)

d. Keragu-raguan+konfirmasi (doubt+proposal / 疑い十もちかけ)

Contoh: Ame? (Hujan?)

Dari penjelasan tersebut di atas bisa ditarik suatu kesimpulan bahwa terdapat dua jenis kalimat deklaratif, yaitu (1) Kalimat Deklaratif (述定文 ‘jutsuteibun’), dan (2) Kalimat Deklaratif-Transmitif (述定文 ‘jutsuteibun’ + (伝 達文 ‘dentatsubun’). Kemudian kalimat deklaratif tidak hanya mengekspresikan sikap penutur tentang sesuatu hal yang diungkapkan, tetapi juga tentang perasaan penutur akan pengaruhnya terhadap lawan bicara.

1. Memberi petunjuk yang berhubungan (Give Association Clues)

Strategi kesantunan Give Association Clues adalah strategi kesantunan dengan cara memberi petunjuk yang berhubungan kepada lawan bicara. Penutur mengujarkan sesuatu yang berhubungan dengan tindakan yang diharapkan dari lawan bicara karena penutur dan lawan tutur sebelumnya telah mengalami suatu pengalaman yang sama.

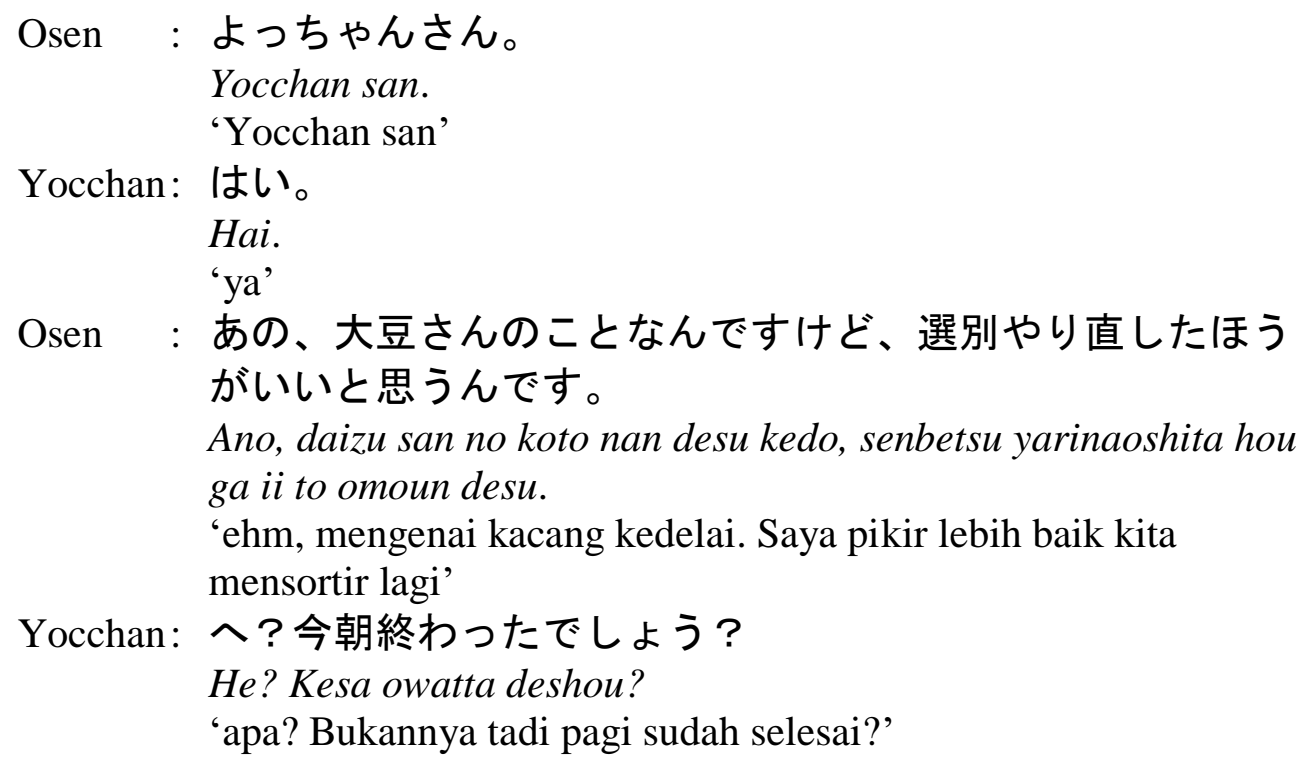


Osen :jん。わちの説明のし方が良くなかったと思うんですけど、 まだよくない大豆さんが混ぜっているみたいで。でも、や り直したらもっともっとうまいみそができますから。 Un. Wachi no setsumei no shikata ga yokunakatta to omoun desu kedo, mada yokunai daizu san ga mazette iru mitai de. Demo, yarinaoshitara motto motto umai miso ga dekimasu kara. 'ya. Mungkin cara ku menjelaskan tidak bagus, sepertinya masih ada kedelai jelek yang tercampur. Tapi, jika kita sortir lagi, makan akan menjadi miso yang jauh lebih enak'

(DJ2/2/19.05-19.38)

Percakapan terjadi antara Osen dan Yocchan. Osen meminta Yocchan membantunya lagi untuk mensortir kedalai yang bagus dan yang buruk untuk pembuatan miso. Padahal sebelumnya pekerjaan tersebut telah selesai dilakukan. Pada tuturan yang digaris bawahi terlihat Osen mengatakan kepada Yocchan bahwa jika kita mensortir lagi kedelainya, maka miso yang dihasilkan akan jauh lebih enak. Sedangkan maksud Osen yang sebenarnya adalah menyuruh Yocchan membantunya lagi untuk mensortir kedelai yang baik dan yang jelek. Tuturan yang diucapkan Osen tersebut tidak ada hubungannya dengan maksud yang sebenarnya ingin disampaikan. Osen sengaja menggunakan tuturan tersebut dengan maksud Yocchan bisa menginterpretasikannya. Tuturan yang diucapkan Yocchan ini terkesan seperti memberikan suatu isyarat atau petunjuk yang berhubungan, karena di hari sebelumnya mereka berdua sudah melakukan penyortiran kedelai-kedelai tersebut. Oleh sebab itu tuturan tersebut dimasukkan dalam kategori strategi kesantunan Give Association Clues.

2. Memberikan isyarat atau petunjuk (Give Hints)

Strategi kesantunan Give Hints ini adalah starategi kesantunan dengan cara memberikan isyarat atau petunjuk kepada lawan bicara. Yaitu penutur mengujarkan sesuatu yang tidak berhubungan dengan maksud yang sebenarnya, ia 
berharap lawan bicaranya dapat menginterpretasikan ujaran yang disampaikan tersebut.

Fujii : 石田。

Ishida.

'Ishida"

Ishida : 藤井さん。

Fujii san.

'Fujii san'

へえ、ここが藤井さんの部屋か。ソファ、ベッド

Hee, koko ga Fujii san no heya ka. Sofa, beddo 'he, jadi ini kamarnya Fujii san. Sofa, tempat tidur'

Fujii ：はい。こういうの苦手なの。私は企画書上げなきゃいけな いし...

Hai. Kouiu no nigate na no. Watashi ha kikakusho agenakya ikenai.

'ini. Aq tidak pandai dalam hal-hal sprt ini. Lagian aku harus menyelesaikan laporan ini'

Ishida : ですよね。出力 1 つと。

Desu yone. Shutsuryoku hitotsu to.

'pastinya. Output 1 ...'

Fujii : ごめんね、手伝わせて。

Gomen ne, tetsudawasete.

'maaf ya, aku mintain tolong'

Ishida : いえいえ、もう他にもなんかあるんならジャンジャンジャ

ンジャン 言ってくださいよ。

Ie ie, mou hoka nimo nanka arun nara, jan jan jan jan itte kudasai yo.

'tidak tidak. Kalau masih ada yang lainnya, langsung bilang saja'

Fujii : じゃ、ドアノブ

Ja, doanobu

'kalau begitu, gagang pintu'

Ishida : へ?

He.

'apa?'

(DJ1/10/00.05-00.45)

Percakapan terjadi antara Fujii dan Ishida. Fujii meminta Ishida datang ke apartemennya untuk memperbaiki beberapa peralatan rumah yang rusak. Pada 
tuturan yang digaris bawahi terlihat Fujii mengatakan kepada Ishida bahwa dirinya tidak mahir dalam hal memperbaiki peralatan yang rusak. Sedangkan maksud Fujii yang sebenarnya adalah menyuruh Ishida Untuk memperbaiki peralatannya yang rusak. Tuturan yang diucapkan Fujii tersebut tidak ada hubungannya dengan maksud yang sebenarnya ingin disampaikan. Fujii sengaja menggunakan tuturan tersebut dengan maksud Ishida bisa menginterpretasikannya. Tuturan yang diucapkan Fujii ini terkesan seperti memberikan suatu isyarat atau petunjuk. Oleh sebab itu tuturan tersebut dimasukkan dalam kategori strategi kesantunan Give Hints.

\section{Praanggapan (Presuppose)}

Strategi kesantunan Presuppose (praanggapan) adalah kesantunan dengan cara penutur menuturkan ujaran yang seluruhnya hampir relevan dengan konteks dan memberikan praanggapan kepada lawan bicara.

\section{Tanaka : 気が済んだ?そんなに向けになるのは相手があたしだか ら? \\ Ki ga sunda? Sonna ni muke ni naru noha aite ga atashi dakara? 'sudah puas? marah seperti itu apa karena lawannya adalah aku?' \\ Fujii ：いや、別にそんなんじゃ。 Iya, betsu ni sonnanja. 'nggak juga. Tidak seperti itu' \\ Tanaka : 言い切れる? 藤井さんはいつも清らかでいいわね。でも、 それ ってすごく器小さいと思うのよ。女として。私 ね荻原にはいい 男になってほしいの。あなた程度 の型にはめられたらかわいそ う。だから、やっぱ り荻原はあなたに渡せない。 \\ Iikireru? Fujii san ha itsumo kiyoraka de ii wane. Demo, sorette sugoku utsuwa chiisai to omou no yo. Onna toshite. Watashi ne Ogiwara ni ha ii otoko ni natte hoshii no. Anata teido no kata ni hameraretara kawaisou. Dakara, yappari Ogiwara ha anata ni watasenai.}


'benarkah? Fujii san bagus ya selalu bertindak lurus. Tapi menurut ku itu sangat terbatas sebagai seorang wanita. Aku ingin Ogiwara menjadi laki-laki yang baik. Aku sangat menyayangkan jika dia berhubungan dengan wanita seperti mu. Oleh karena itu, aku tidak akan memberikan Ogiwara kepada mu'

(DJ1/5/33.49-34.35)

Percakapan terjadi antara Tanaka dan Fujii. Fujii terlihat sedikit marah kepada Tanaka mengenai urusan pekerjaan, meskipun sebenarnya itu bukan hal yang besar dan perlu dipermasalahkan. Melihat hal tersebut, Tanaka menghampiri Fujii dan menegurnya. Menurut Tanaka, dengan melihat sifaf Fujii yang seperti itu, Fujii bukanlah seorang wanita yang ideal untuk Ogiwara. Pada tuturan yang digaris bawahi nampak Tanaka mengatakan kepada Fujii bahwa dia tidak akan memberikan Ogiwara kepadanya. Tuturan tersebut merupakan tuturan tidak langsung dan mempunyai makna lain dibaliknya. Makna sebenarnya adalah Tanaka meminta Fujii untuk menjauhi Ogiwara atau tidak mendekati Ogiwara lagi. Tuturan tersebut sangat relevan dengan makna yang sebenarnya ingin disampaikan. Oleh karena itu tuturan tersebut dapat digolongkan ke dalam tuturan dengan strategi kesantunan Presuppose (praanggapan).

\section{SIMPULAN}

Berdasarkan analisis tentang kesantunan off record tindak direktif dalam kalimat deklaratif bahasa Jepang terhadap dua serial drama Jepang ditemukan 106 data. Dari jumlah data tersebut 13 jenis strategi off record ditemukan, yaitu: give association clues, give hints, presuppose, use tautologies, under state, use rhetorical questions, overstate, use contradiction, use metaphors, be vague, be incomplete (use ellipsis), be ironic, dan over generalize. Sedangkan 2 jenis strategi yaitu be ambiguous dan displace hearer tidak ditemukan. Kemudian, strategi yang paling banyak muncul adalah strategi kesantunan give association clues atau memberi petunjuk yang berhubungan dengan jumlah sebanyak 33 data. http://journal.unesa.ac.id/index.php/paramasastra | 238 
Desy Irmayanti, Kesantunan Tindak Direktif... (hIm.222-239)

\section{DAFTAR PUSTAKA}

Brown, Penelope and S.C. Levinson. (1987). Politeness: Some Universals in Language Usage. Cambridge: Cambridge University Press.

Kindaichi, Haruhiko. (1988). Nihongo (Ge). Tokyo: Iwanami Shoten.

Kreidler, Charles W. (1998). Introducing English Semantics. London: Routledge.

Leech, Geoffrey. (2011). Prinsip-prinsip Pragmatik. Jakarta: Penerbit Universitas Indonesia.

Rahardi, R. Kunjana. (2005). Pragmatik: Kesantunan Imperatif Bahasa Indonesia. Jakarta: Erlangga.

Ramlan. (1996). Ilmu Bahasa Indonesia: Sintaksis. Yogyakarta. Karyono.

Sudjianto dan Ahmad Dahidi. (2012). Pengantar Linguistik Bahasa Jepang. Jakarta: Kesaint Blanc.

Yule, George. (2006). Pragmatik. Yogyakarta: Pustaka Pelajar. 